

\title{
NEAR-FIELD MASS TRANSTER IN GEOLOGIC DISPOSAL SYSTEMS: A REVLW
}

\author{
T. H. Pigford and P. L. Chambré
}

Department of Nuclear Engineering and Lawrence Berkeley Laboratory, University of California, Berkeley, CA 94720

\begin{abstract}
A primary purpose of performance assessment of geologic repositories for radioactive waste is to predict the extent to which radioactive species are released from the waste solids and are transported through geologic media to the environment. Reliable quantitative predictions must be made of rates of release of radionuclides from the waste into the rock, transport through the geologic media, cumulative release to the accessible environment, and maximum concentrations in ground water and surface water. Here we review theoretical approaches to making the predictions of near-field release from buried waste solids, which provide the source terms for far-field release. The extent to which approaches and issues depend on the rock media and on regulatory criteria is discussed.
\end{abstract}

\section{INTRODUCTION}

Designers of geologic disposal systems for solid waste must predict the long-term time-dependent rate of dissolution of toxic contaminants in ground water, to provide the source term for predicting the later transport of these contaminants to the environment. If a container is provided to protect the waste from ground water for an extended period, it is necessary to pred: $:$ the time when the containet allows contaminants to be relcased to ground water, and it may be necesoary to predict the rate of such releases through partly failed containers. Mass-transfer analysis is being used to predict rates of dissolution and release of radioactive constituents in future repositories for high-level radioactive wasce, and it has been applied to predict the life of a copper container for high-level tadioactive waste.

The L. S. Nuclear Regulatory Commission' ${ }^{2}$ has specified numerical limits for the rate of release of radioactive constituents into rock surrounding packages for high-level waste, including unreprocessed spent fuel and reprocessing waste, and it has specified the required time for substantially complete containment of thr: radioactive constituents by the waste container. Other nations have not imposed such specific requireinmits on the waste package, but prediction of these same features will be needed for the overall prediction of repository performance.

IJere we summarize the evolution and application of near-field mass-transfer analyses in high-level-waste programs.

\section{HISTORICAL}

I ntul the introduction of mass-transfer analysis for predicting long-term performance of waste packages In is repustory. It had been generally assumed that the rate of release of cont:minants from a waste solid would be rontrolled by the pate of chemical reaction of that waste solid with ground water. Samples of wiste soluds wer. "xposied to sirnulated ground water in laboratory leach studies. where the rate of release thto liw witus would be controlled by chemical reaction, by degradation of the solid, or by requency of r.plaring the leachant. In 1978 Neretnieks ${ }^{2}$ suggested that rate of dissolution in a geologic environment mught be limuted instead by solubilities and by rate of diffusive-convertive transport of dissolved species from the waste surface.

Application of mass transfer analysis in the U.S. programs was stimulated by observations of the Na- 
tional Research Council's Waste Isolation System Study, ${ }^{3}$ first made in 1981, that there was little validity in assumptions that the long-term dissolution rates in a geologic repository could be predicted from laboratory data on leach rates of waste samples. Laboratory leach data are empirically correlated, at a given temperature, with time of exposure and the concentration of dissolved species in the liquid. The latter depends on correlating parameters such as the ratio of sample surface to the volume of wellmixed liquid, liquid replacement frequency, etc. The actual processes of dissolution are reaction of the waste solid with ground water at the waste surface and diffusion and convection of the dissolved species from the surface into the ground water in the surrounding rock. In this open system of the repository there is no well-defined volume of well-mixed liquid as in the closed-system laboratory experiments. Here the concentration in the surface liquid depends on the mass-transfer properties of the surrounding medium.

Recognizing that the waste-solid matrix and most of its solid constituents are of low solubility, we first sought an upper limit on the net rate of dissolution by assuming that the solution at the waste surface is saturated with the individual waste constituents. The exact analytical solutions ${ }^{4}$ for the time-dependent mass transfer rate from a waste solid in contact with saturated porous rock showed that the limiting masstransfer rates for the buried waste are so slow that the actual dissolution rate is expected to be limited by diffusive-convective transport in the pores in the rock and not by chemical reaction rate at the waste surface. By comparing these predicted diffusive-convective mass transfer rates with laboratory dissolution data obtained under conditions wherein solid-liquid reaction rate is controlling, it was concluded that the basic rate constants for the solid-liquid reaction were rapid enough, for the waste solids then studied, that the dissolved concentration in the surface liquid would be very close to the saturation concentration. This conclusion was valid for borosilicate glass waste, which had been extensively tested in laboratory experiments. It has since been demonstrated to be valid for the dissolution of uranium dioxide in spent fuel.

Mechanistic analysis of mass-transfer is based on well-established theory of diffusive-convective transport. Its application requires experimental measurement of well-defined parameters such as porosity, solubility, diffusion coefficient, and pore velocity. It relies on no arbitrary and adjustable parameters from empirical rate measurements; reliance on such parameters would undermine the reliability of the theory to predict dissolution rates in the long-term future. Mase-transfer theory can be used to predict the long-term steady-state dissolution rate in a repository, as well as the highet transient dissolution rates that can exist for hundreds and thousands of years after the waste-solid comes in contact with water. The first analysis in t lue U.S. program assumed a waste solid in direct contact with porous rock. The more realistic situations of harkfill between the waste and rock, rock with discrete fractures as well as pores, and the effects of waste consticuents of high solubility were among the many extensions of mass-transfer analysis left for future study.

The first results from this new m.ss-transfer theory were published in $1982,4.5$ and the theory was lighlighted by tíe Waste Isolation System Study as a recommended approach for predicting the long-term performance of waste solids in a repository.

Nieretuitks ${ }^{2}$ used simplified techniques of mass-transfer analysis to predict the steady-state rate of oxiitition of the copper containers and to predict the rate of waste dissolution for the Swedish KiBS studies. Th+ validity of several approximations in his estimates can now be evaluated from the more accurate timedripendent antilytical solutions developed by us.

Sistuseryuently, near-field mass-transfer calculations have been used for the three U.S. waste-isolation projects, ${ }^{5,7}, 9,9$ itud some of the new Berkeley analytical tools ${ }^{5,13}$ have been incorporated in the Pacific Northwist Laboratory's computer code ${ }^{10}$ for waste-package performance ussessment. Near-field mass-transfer athalyses and calculittions are now incorporated in the Canadian ${ }^{11}$ and Swiss ${ }^{12}$ repository prograns.

\section{MASS TRANSFER FROM A WASTE SOLID INTO POROUS ROCK}

\section{Inlustrative results}

Figure 1 illustrates some results obtained from mass-transfer theory. flere an equivalent snherical waste package contiaining spent fuel is surrounded by, and in direct contact with, saturated porous rock. Ground 
water flow is slow enough that near-field transport is controlled by molecular difusion, typical of expected conditions in the U.S. repository programs. The fractional release rate, defined here as the mass rate of dissolution of a radionuclide species divided by the initial inventory of that species in the waste solid, is plotted against the time since the beginning of dissolution. For long-lived species, such as U-234, Cs-135, and I-129, this is numerically equal to USNRC's fractional release rate based on the inventory of such species at 1000 years.

The lower curve is for the solubility-limited dissolution of species released congruently with uranium from $\mathrm{UO}_{2}$ matrix, calculated from the exact analytical solutions ${ }^{5}$ for the time-dependent mass transfer, assuming saturation concentration of the dissolved uranium in ground water at the waste surface and for a uranium solubility of $0.001 \mathrm{~g} / \mathrm{m}^{3}$ for reducing conditions. ${ }^{3}$ Fractional release rates of such congtuently dissolving species with half lives lower than that of uranium will depart from and fall below the uranium curve at times of the order of their half lives. These fractional release rates into the rock are well below the USNRC guideline of $10^{-5} / \mathrm{yr}$. Under oxidizing conditions the uranium solubility can increase markedly, by five or six orders of magnitude, but not enough for the predicted rate of net dissolution to exceed the guideline limit.

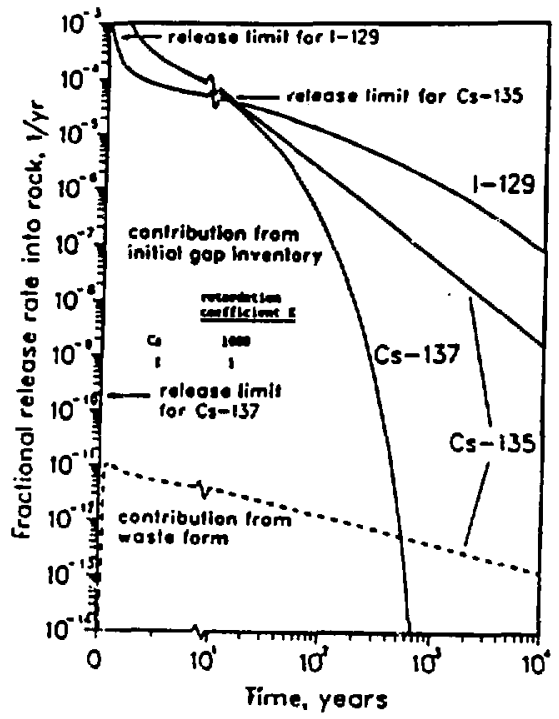

Figure 1. Fractional release rates into rock as a function of time (early container failure, $10 \mathrm{~cm}$ of void water, $1 \%$ of total cesium and iodine in sap. $D=0.12 \mathrm{~m}^{2} / \mathrm{yr}$.

'The upper curves of Figure 1 apply to the release of the more soluble species, e.g., cesium and iodine, that were released from the $\mathrm{UO}_{2}$ matrix during reactor operation and are present in $\mathrm{UO}_{2}$ grain boundaries ind pores and in the fuel-cludding gaps. The curves are calculated from the analytical solutions ${ }^{13}$ for the transient diffusive snass transfer into surrounding porous rock, given a specified initial amount of soluble 
species dissolved in ground water that has filled voids in the waste package. Assuming that 1 percent of the total inventory of these soluble species are in this readily soluble "gap activity", the predicted mass rates of release into the rock divjded by the total initial inventory of each species are orders of magnitude greater than the fractional releases from matrix dissolution. Because the 1000 -year inventories of cesium and iodine, expressed in curies, are each less than 0.1 percent of the total curie activity of the waste at 1000 years, numerical limits for fractional release rate of these species can be calculated ${ }^{24}$ from USNRC's numerical criteria for low-inventory constituents. These calculated limits, applicable when the fractional release rate is based on the inventory at the time of emplacement, are shown in Figure 1. The limits for Cs-135 and I-129 are exceeded for an individual waste package only during the first few days of dissolution and may be easily met for the average waste package if not all waste-package containers fail at the same time. The limit for $\mathrm{Cs}-137$ is exceeded if an appreciable number of waste containers fail not long after emplacement, but it is easily met if all waste containers remain intact for 300 years or more.

The time-dependent moss release rates used to construct Figure 1 can also be used as time-dependent source terms for far-field transport analysis.

Subsequent sections of this report discuss possible limitations of the analyses used to produce Figure 1 and also discuss the effects of additions to the waste-package-rock system that may be more realistic in some situations, such as backfill, more rapid ground water flow, time-dependent temperatures, rock fractures, etc.

\section{Mass Tranafer for Solubillty-LLmited Specten, Controlled by Diffusion in Pore Liquid}

The illustrative results in Figure 1 are calculated from the equations for time-dependent mass transfer by molecular diffusion, ${ }^{5,13}$ applicable for the low ground-water flow rates typical for repositories in basalt, tulf. or salt. Exact analytical solutions for the time-dependent rate of mass transfer from waste forms of various shapes has been obtained. ${ }^{5}$ The steady-state form of that equation for a low-solubility long-lived species, assuming constant saturation concentration $N^{*}$ in the liquid at the waste surface and assuming that the waste solid is surrounded by poraus rock, is:

$$
f_{i}=\frac{\beta c D N_{i}^{*}}{n_{i}}
$$

wlywe $f_{i}$ is the fractional dissolution rate of species $i, c$ is the porosity of the rock, $D$ is the diffusion coefficient in pore water, and $n_{i}$ is the concentration of the specieg in the waste solid. $\beta$ is a geometrical factor that call be calculated from the waste-form dimensions and is $3 / R^{2}$ for a spherical waste of radius $R$.

It is also important to examine the higher release rates that occur before steady state is reached and thit can occur with radioactive species, as predicted by the exact analytical solutions. ${ }^{5}$ If the waste solid rill react with ground water rapidly enough to maintain near-saturation in liquid at the waste surface, the early rate of mass transfer will be high, and it will decrease as the concentration profile penetrates farther from the waste surface. Greater sorption retardation increases the time to steady state, and it increases the transient dissolution rate because sorption steepens the concentration gradient.

\section{Solubitity-Limlted Mase Transfer With Dlffunlon and Advection}

We have ${ }^{5}$ also developed the exact analytical solution for the time-dependent mass transfer when both liffusive and convective transport are important. The mathematical analysis makes use of the known distribution of ground water velocities around an infinite cylinder and through the pores of the surrounding rock. An iLiymptotic form of that analytical solution, applicable to steady-state mass transfer of a solubility-limited -tialile ipecies with steady flow around a long waste cylinder surrounded by porous rock, is:

$$
f_{i}=\frac{8 \pi N_{i}^{-}(D U)^{1 / 2}(1+R / L)}{(\pi R)^{0 / 2} n_{i}}, \quad P e>4
$$

The Pretet number $P_{e}$ is given by $U R / D$, where $U$ is the ground water pore veloctly upstream of the waste solid, $R$ is the radius of the waste solid, and $L$ is the length of the waste cylinder. 
Equations for the steady-state dissolution rate that are similar in form, but not identical, to Equation (2) have been obtained by others $2,7,8,15$ using boundary-layer approximations. However, only the exact mathematical solution provides a criterion of validity of the asymptotic steady-state equation, Equation (2). Ignoring the limit of validity and applying the steady-state asymptotic equation, or its equivalent $7,8.15$, to predict mass transfer rate at the very low velocities expected in U.S. repositories is not valid and will give nonconservatively low estimates of the dissolution rate.

Correct and incorrect predictions of fractional dissolution rate over a wide range of Peclet numbers are illustrated in Figure 2, calculated for solubility-limited mass transfer of $\mathrm{UO}_{2}$, from a spherical-equivalent waste solid of radius $48.6 \mathrm{~cm}$. The upper curve is estimated at 100 years, with a retardation coefficient of 100 . The lower curve is for steady state. The dotted curve shows an incorrect extrapolation of the steady-state $P e^{1 / 2}$ dependency from the high $P e$ region to the pore velocities of a few millimeters per year, ${ }^{7}$ expected in the tuff and basalt repositories, resulting in underestimates of the release rate by several orders of magnitude. The porosity used was 0.1 , the diffusion coefficient $10^{-5} \mathrm{~cm}^{2} / \mathrm{sec}\left(315 \mathrm{~cm}^{2} / \mathrm{yr}\right)$ and the $\mathrm{UO}_{2}$ solubility in an oxidizing environment $5 \times 10^{-5} \mathrm{~g} / \mathrm{cm}^{3}$.

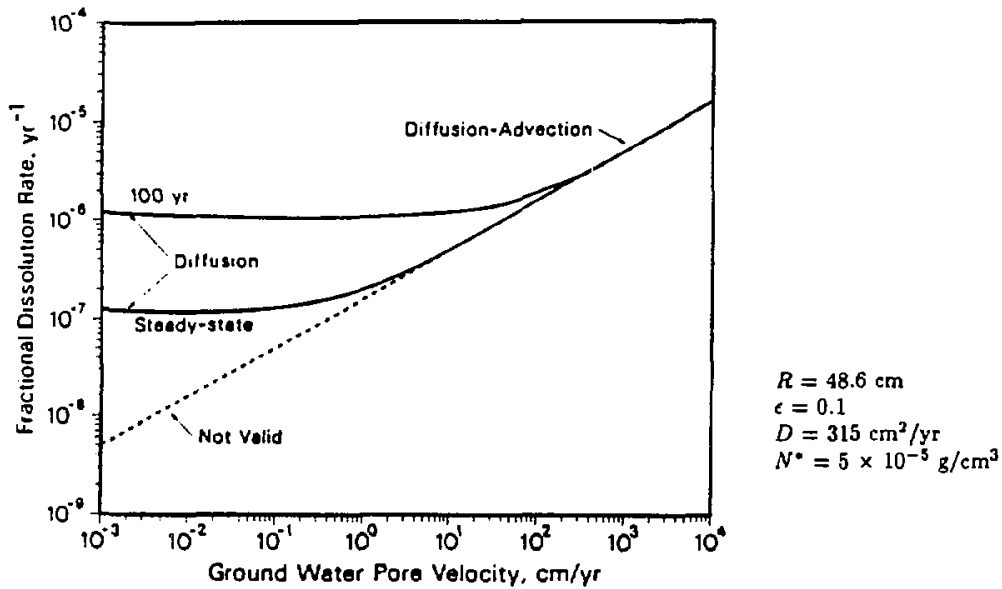

Figure 2. Extrapolations of fractional dissolution rates for $\mathrm{UO}_{2}$ to low flows in an oxidizing enviconment.

For an assumed waste radius of $48.6 \mathrm{~cm}$ and an upper-limit value of the diffusion coefficient of $10^{-5}$ $\mathrm{cm}^{2} / \mathrm{sec}\left(315 \mathrm{~cm}^{2} / \mathrm{yr}\right)$, which neglects tortuosity corrections, the ground water pore velocity must be about 3 $\mathrm{m} / \mathrm{yr}$ or greater for the steady-state equation (2) to be applicable. Although such velocities may be expected in some repositories, the ground water velocities expected for prospective U.S. repositories in basalt, tuff, and salt are orders of magnitude lowet. However, if tortuosity reduces the diffusion coefficient a hundred-fold, the steady-state equation (2) is applicable to pore velocities as low as $3 \mathrm{~cm} / \mathrm{yr}$, still larger than those predicted for the U.S. repositories. For the lower velocities the equations for diffusion-controlled release are applicable.

Equation for the time-dependent fractional release pate for a radioactive specieg with a constantconcentration hundary condition are also given. ${ }^{5}$ The early rate of mass transfer will be high, and if 
will decrease as the concentration profile penetrates farther from the waste surface. With no decay, steady state is reached in as little as a year or not until a few hundred years, depending on the magnitude of the retardation coefficient $K$. Greater sorption retardation jncreases the time to steady state, ard it increases the transient dissolution rate because sorption steepens the transient concentration gradient. Advective. transport shortens the time to reach steady state.

Increasing the radioactive decay constant $\lambda$ incresses the rate of mass transfer by steepening the concentration gradient near the waste surface. Incressing the modified Damkohler modulus $K \lambda R / U$ from zero, for no decay, to 10 causes a more than fourfold increase in the steady-state dissolution rate, and it decreases the time to reach steady state. For a mixture of stable and ungtable isotopes oi a given element, the appropriate half life is the effective balf life of the isotopic mixture at the time the decay correction is to be applied. Decay corrections are more important when mass transfer is controlled by difiusion, i.e., when the pore velocity is so low that convection does not affect dissolution.

\section{Dependence on Waste-Form Materlal Propertlea: Bolld-Lquid Renctlon Rate}

The analytical solutions discussed above for solubility-limited mass transfer have a clear meaning for a single-component waste solid that has a well-defined solubility appropriate to the chemical environment at the waste surface. Solubility is a conservative upper-limit boundary concentration, if effects of colloids can be neglected. The result is a bounding estimate of the release rate from the waste solid that does not depend on the particular chemical form of the waste solid unless that chemical form itself affects the solubility of the single-component species. Effects on other constituents within the waste solid will be discussed later.

In many studies it has been assumed that waste forms can be developed that will perform better in a repository because of low rates of chemical reaction of the waste solid with ground water. The proposition is reasonable but has been made without quantification of the effect of chemical reaction rate on the performance of a waste solid in a repository. In the mass-transfer analyses discussed above for solubility-limited species, it has been implicitly assumed that the solid-liquid reaction rate is rapid enough so that the dissolved material is at, or very near, the solubility limit at the waste surface. Actual chemical reaction rates do not enter that analysis, and the bounding results from that analysis are not influenced by factors which can affect solid-liquid reaction rate, such as interior cracks in the waste solid, devitrification if a glass, and ather such mechanisms that could increase the surface area for solid-liquid reactions.

To illustrate an approach to determine the effect of solid-liquid reaction rate on the rate of mass transfer to ground water in a geological environment, an analytical solution for the rate of diffusive mass transfer of a dissolved waste into surrounding porous rock was developed, ${ }^{17}$ using chemical reaction rate as a boundary condition instead of assuming a solubility-limit boundary concentration. Leach-rate data ${ }^{18}$ for borosilicate glass waste suggest that the solid-liquid reaction rate can be approximated by a zero-order forward reaction and a back reaction that is first order with respect to the concentration of dissolved silica. The continuity boundary condition at the waste-liquid interface in a repository specifies that the current of dissolved species at the waste outer surface equal the net rate of dissolution by solid-liquid reaction:

$$
-\mathrm{C} D \frac{\partial N(R, l)}{\partial \mathbf{r}}=j_{0}\left(1-\frac{N(R, t)}{N^{*}}\right), \quad t>0
$$

where.$(\Omega, t)$ is the concentration of dissolved species in liquid at the spherical waste surface and $j_{0}$ is the "xperimental forward reaction rate of the dissolved species per unit surface area. The forward reaction rate is measured when the surface is in contact with a liquid that contains none of the dissoived species being considered in Eq. (3)

L'sing the above boundary condition togecther with the diffusion equation and with other side conditions, tle time-dependent concentration in the liquid in the porous rock and the time-dependent net dissolution rate $j(R, t)$ are obtained ${ }^{17}$. At steady state the concentration and mass-transfer rate at the surface are:

$$
N(R, \infty)=N^{*} \frac{\alpha}{1+\alpha}
$$




$$
j(R, \infty)=\frac{j_{0}}{1+\alpha}
$$

where

$$
\alpha \equiv \frac{j_{e} R}{\varepsilon D N^{*}}
$$

Eqs. (4) and (5) show that when $\alpha$ is large $N(R, \infty) \approx N^{*}$ and $j(R, \infty) \approx \epsilon D N^{*} / R$. Under these conditions the net dissolution rate is controlled by diffusion in the exterior field. When $\alpha \ll 1$ the surface concentration $N(R, \infty)$ is much less than the saturation concentration and the net mass-transfer rate is controlled by the solid-liquid reaction and is equal to $j_{0}$. For intermediate values of $\alpha$ one must use Eqs. (4) and (5) for steady state and the analytical solution for transient values of $N(R, t)$ and $j(R, t)$. The analysis of the surface concentration and dissolution rate with species decay in the waste form and in the exterior field has also been treated.

To illustrate, we ussume a waste glass cylinder of radius $0.15 \mathrm{~m}$ and length $2.4 \mathrm{~m}$, resulting in an equivalent sphere of radius $0.44 \mathrm{~m}$. From the laboratory leach data ${ }^{18}$ for PNL 76-68 borosilicate glass we derive the following effective values for silica at $90^{\circ} \mathrm{C}: j_{0}=1.18 \mathrm{~g} \mathrm{SiO} / \mathrm{m}^{2} \mathrm{day}$, and $N^{*}=200 \mathrm{~g} \mathrm{SiO}_{2} / \mathrm{m}^{3}$. For an estimated diffusion coefficient of silicic acid in water at $90^{\circ} \mathrm{C}$ of $2 \times 10^{-2} \mathrm{~m}^{2} / \mathrm{d}$ and neglecting tortuosity corrections, and for a rock porosity of 0.01 , we estimate $\alpha=1240$. Assuming no sorption of silica on the rock ( $\mathrm{K}=1$ ), the estimated time to steady state is 320 years. From Eq. (4) $N(R, \infty)=0.999 N^{*}$ for silica. The steady-state mass transfer of silica will be controlled by exterior-field diffusion, and assuming saturation concentration $N^{*}$ of silica at the waste surface is not only conservative but is also realistic.

Our more detailed illustration ${ }^{17}$ shows the surface mass flux of silica and the surface concentration as a function of time. If saturation at all times were assumed the early mass-transfer sate would be infinite, a result not physically reasonable. It is in these early times that the solid-liquid reaction rate is important for the dissolution of a low-solubility solid matrix. The actual surface concentration is initially zero, and it grows with time at a finite rate determined by the solid-liquid reaction rate. Within about seven minutes after bare glass waste has been placed in contact with low-porosity water-saturated rock the concentration of nonsorbing silica in the surface liquid will have reached 82 percent of saturation and the mass-transfer rate will be within 5 percent of that predicted for constant saturation at the surface, assuming no silica sorption in the rock. If silica sorbs with an assumed retardation coefficient of 100 , this time is increased to 700 minutes.

The time to reach near-saturation concentration will be longer if there is stagnant liquid between the waste surface and the exterior porous medium. This time delay is easily added to the theory because the intervening liquid is likely to be well mixed.

Van Luik et al. ${ }^{19}$ list values of $j_{0}$ for unirradiated and irradiated $\mathrm{UO}_{2}$ in deionized water and in brine at various temperatures. They adopt a conservatively low valixe of $j_{0}=0.005 \mathrm{~g} / \mathrm{m}^{2}$ day. Assuming that uranium dissolution obeys a simple concentration dependence as described in Eq. (3), adopting uranium solubilities ranging from $2 \times 10^{-2} \mathrm{~g} / \mathrm{m}^{3}$ at $\mathrm{pH} 11$ to $2 \times 10^{-8} \mathrm{~g} / \mathrm{m}^{3}$ at $\mathrm{pH} 6,{ }^{19}$ and for other parameters the same as used in the above example for silica, we obtain an estimated flux ratio for the spent-fuel matrix of 5 $\times 10^{4}$ to $5 \times 10^{5}$, greater by one to seven orders of magnitude than that estimated for silica from borosilicate gliss. If these data are correct, uranium dissolution in a geologic repository is likely to be controlled by exterior-field mass transfer and not by chemical reaction rate. More data are needed on solid-liquid reaction rate as a function of concentration of dissolved uranium and of temperature.

In a separate paper in these proceedings ${ }^{20}$ we present a new analysis of the role of chemical reaction when steady-state mass transfer from the waste solid can be controlled by both advection and diffusion. For borosilicate glass wiste in the temperature range of $57^{\circ} \mathrm{C}$ to $.70^{\circ} \mathrm{C}$, the steady-state dissolution rate is affected by chenical reaction rate only a: Peclet numbers well above 100 , far beyond any flow rate reasonably expected in a repository. 


\section{Relense of Other Specles From a Low-Solubllity Waste Matrl}

If there is no preferential leaching of other chemical elements contained in the low-solubility waste matrix, all constituents in the matrix will be released congruently as the matrix dissolves. For a congruently released species that dissolves when released from the waste solid, the instantaneous fractional dissolution rate of that sf and will be controlled by the matrix solubility. For rigor, the fractional dissolution rate must be interpreted here as the instantaneous mass rate of dissolution of a species divided by the inventory of that species at that same instant. Thus, if congruency of release and dissolution can be established, the equations for solubilitylimited dissolution of a single-component waste solid can be applied to the waste matrix, thereby yielding the fractional dissolution rates of the constituents.

Leaching experiments on borosilicate glass containing waste actinides have shown that some of the contained actinides dissolve less rapidly than would be predicted by congruency with the silica matrix, and saturation concentrations of neptunium and plutonium in leach solutions are found to equal the solubilities of the stable compounds formed when these actinides react with the aqueous leachant. ${ }^{21}$ This suggests that actinides released when the silica dissolves form precipitates at the waste surface. For any such constituent whose dissolution rate is limited by its own solubility, the fractional dissolution rate can be predicted by applying the single-component mass-transfer equations developed by us, using the measured solubility of that species for its boundary concentration. The results will be valid if the instantaneous fractional dissolution rate of that species, based on its own solubility, is less than the instantaneous fractional dissolution rate of the waste matrix.

If the low-solubility constituent whose release is controlled by its own solubility is an isotope of an element with other isotopes present, the solubility concentration in the mass-transfer equation should be replaced by the elemental solubility multiplied by the isotopic fraction of the isotope of interest. This can be formulatad exactly if the radionuclide of interest is a minor isotopic constituent of its elemental species in the waste solid. It is an approximation if the radionuclide of interest is present in an isotopic concentration similar in magnitude to that of another isotope of that element but of different half life.

In applying the mass-transfer theory to the dissolution of borosilicate glass waste in a typical repository environment, it is predicted ${ }^{3,22}$ that the actinides in the waste will dissolve at a rate limited by their own solubilities. However, for unreprocessed spent fuel, the low solubility of uranium in reducing conditions and the high concentration of uranium in the waste result in a predicted fractional dissolution rate of the waste matrix in a repository environment that is much lower than for borosilicate glass. If the contained coustituents are released congruently, they are predicted to dissolve at a rate limited only by uranium solubility. To make reliable predictions of the performance of spent fuel in a repository, it is important to establish experimentally the extent to which constituents in the uranium dioxide matrix dissolve congruently. 'The experiments should be performed with a leachant at near-saturation concentration with respect to the waste matrix, because this is the surface-liquid concentration predicted for the repository environment.

The instantaneous fractional release rate of a species limited by its own solubility is predicted to be proportional to the solubility of that species divided by its concentcation in the waste solid. Species present. only in sinall or trace concentrations are more likely to be limited in dissolution rate by the matrix solubility. Low-solubility radioactive species initially present in suffient concentrations to be dissolution-rate-limited by their own solubility can eventually decay to a concentration low enough to be dissolution-rate-limited by the mat rix solubility.

\section{Diffustve Mass Transfer of Soluble Specles}

In a sprent-fuel waste package the soluble cesium and iodine accumulated in fuel-cladding gaps, voids. inut grain boundaries of spent fuel rods are expected to dissolve rapidly when groundwater penetrates the fuel cladding. Even though dissolution may be rapid, the rate of release of these soluble species from the waste package will be limited by the rate of mass transfer of the dissolved species into the surrounding porous media. We have developed the analytic solution for the fractional release rate of a readily soluble ridlioactive species, assumiug instantaneous dissolution of the soluble species into a volume of ground water 
that has penetrated in the waste package voids at $t=0$, and assuming that the ground-water flow rate is small enough that mass-transfer into surrounding poruus rocki is controlled by molecular diffusion.

The results are illustrated in the upper curves in Figure 1, assuming that one percent of the total cesium and iocine is readily soluble "gap" activity and assuming void water equivalent to a $10-\mathrm{cm}$ layer betweer. the fue! rods and the surrounding rock. With these assumed parameters, the release rates of the soluble activity are more than 107 -fold greater thar the congruent release rates of these same species from the solubility-limited waste matrix. For early times the fractional release rates of cesium- 135 and cesium- 137 are almost equal, but the cesium-137 release rate decreases rapidly because of radioactive decay, whereas the release rate of $3 \times 10^{6}$-year cesium-135 is characteristic of a long-lived or stable species. Because of the assumed negligible sorption of iodine in the surrounding rock, the early fractional release rate of $1.7 \mathrm{x}$ $10^{7}$-year jodine-129 is lower than the rates of strongly sorbing cesium, but the less rapid early depletion of iodine in the void water : ssults in a greater fractional release rate of iodine after about 20 years.

\section{OTHER ASSUMPTIONS IN THE MASS-TRANSFER THEORY}

\section{Effect of a Llquid-Filled Annulus Between Wate and Rock}

The mass-transfer analyses discussed above assume that the waste solid is in contact with porous rock containing ground water. The assun.ption of a constant solubility-limit boundary concentration for lowsolubility species has been discussed above. The theory assumes conservatively that the corrosion-resistant. container of the waste package has failed and that its corrosion products offer no resistance to mass transfer. If there is a liquid-filled annulus between the waste package and the rock, or between the waste solid and the rock, the mass-transfer equations are still applicable, provided there is no appreciable convective flow chrough the annulus. It is reasonable to assume that the liquid between the, waste solid and rock is well mixed, so the dimensions of the borehole should be used for the geometrical parameters in the mass-transfer equations: The effects of convective transport in the annulis and convective flow through the waste solid have not been analyzed.

\section{Effect of Flow Dlrection and Geometry}

Extensions that include the effect of a porous backfill are described later. The analyses described above have assumed that ground water flows normal to the cylindrical axis of a waste paclage. Other flow directions are possible in a repository. We have considered flow parallel to the axis, as well as other waste-form geometries, and have shown that predicted dissolution rates are not significantly different.

\section{Hydrodynamic Disperaton}

It has been suggested by some ${ }^{16}$ that because of hydrodynamic dispersion the effective diffusion coefficient that appears in the analytical solutions should be a value greater than that for molecular diffusion. However, experimental data ${ }^{23,24}$ for eftective diffusion coefficients in packed columns show that for the ground water velocities and dimensions typical for individual waste packages the value for molecular diffusion should be used. At locations far enough removed from the waste surface for hydrodynamic dispersion to bccome important, the concentration gradients are too small to asect the mass transfer from the waste surface. IIovever, if the same governing equations were to be applied to mass transfer over greater distances, the uffect of hydrodynamic dispersion should be considered. The effective diffusion coefficient will increase with distance, :equiring equations for diffusive-advective transport with a space-dependent diffusion coefficient, stuch as that developed by us. ${ }^{25}$

\section{Effect of Radionetloe Decas}

The analysis discussed above were developed for radionuclides with no radioactive-decay precursors. Some of the radionuclides important in repository performance assessment ire continuously generated by decay of precursors, e,g., Ra-226 from U-234 and Th-230, and Th-229/Ra-229 from Np-237 and U-233. It is 
not necessarily conservative to apply the mass-transfer equations for a species with no precursor separately to each member of the decay chain, assuming that each species is at its solubility limit in gr: und water near the waste surface ${ }^{26}$ Decay of a precursor in the transport field can cause solubility-limited concentration of its daughter to occur in the field further from the waste surface, resultirg in greater rates of masstransfer into the rock. This is particularly important when mass-transfer theory is used to predict the rate of transport through backfill, or through other intervening diflusing media, into surrounding rock. The greates peretration of a long-lived precursor through the backfill is a means for a shorter-lived daughter to appear at appreciable distances from the waste surface. A near-field mass-trensfer analysis appiicable to the simultaneous diffusive transp, $\mathrm{rt}$ of a radionuclide cisain has been developed and is described later.

\section{Local Sorption Equibb:ium}

Most of our analysir, assumes local sorption equilibrium, with a constant retardation coefficient. Mass transport without local chemical equilibrium between liquid and solid phases has been analyzed in a previous report. ${ }^{27}$ Mass transfer with local sorption equilibrium but with a concentration-dependent sorption distribution coefficient is discussed elsewhere in this report.

\section{Surface Diffusion}

Most of our analysis assumes no diffusicn of sorbed species on or in the solid phase. However, some experiments with selected species and solids have demonstrated appreciable surface diffusion of adsorbed species. For accurate predictions of mass trïnsfer an experimentally determined diftusion coefficient is desirable, rather than using the upper-limit value usually adopted in our numerical illustrations. In making such measurements, it is important to check also the possibility of surface diftusion. The mass-transfer equations can be reformulated if such measurements indicate that su-face diffusion need be considered.

\section{Interference from Other waste Pacticages}

Most of our analysis of mass transfer from individual waste packages conservatively neglects the overlapping concentration fields resulting from species dissolved from nearby waste packages. For high-level waste packages separated by several meters the concentration fields are not expected to overlap enough in the near field to significantly reduce the mass transfer from an individual package.

Although nearby waste packages do not appreciably affect the dissolution and release rates, the overlapping concentration fields do affect the calculation of far-field transport from arrays of waste packages. Our analyses of concentration fields fiom arrays of waste packages $27,28,29$ show a near region in which the concentrations vary greatly in the direction transverse to ground-water flow, an intermediate region in which the array can be treated as an infinite plane source of dissolving species of the same areal scurce strength, and $a$ far-field region in which the array can be treated as a plane source of finite extent. The array equations have been developed for both porous and fractured media. These intermediate-field analyses will be useful to repository projects in making detailed predictions of releases to the environment.

\section{Porous or Fractured Rock}

In the inass-transfer analysis discussed above, and extensions of these solutions described in some of the following sections, we assume that the rock surrounding the waste solid can be reasonably characterized as a prorous solid. The effect of rock fractures is discussed later.

\section{Constant Temperature}

The solutions described above assume that the waste solid and surrounding rock are at a constant and spatially uniform temperatire. Extensions to account for time-dependent temperatures expected if the waste solid is exposed to ground water when the repository is heated by radioactive decay have been developed. Our mass-transfer equations that predict the rate of diftusive-controlled dissolution of a lowsolubility waste solid surrounded by porous rock can be applied in integral form to predict the effect of 
a time-dependent repository temperature on the dissolution rate. We assume, conservatively, that at any time $t$ the waste and rock are at a spatially uniform temperature equal to the temperature at the surface of the borehole. Time-dependent rock temperatures at the borehole surface are specified from a calculation of transient heat conduction. From these data, from data on the change of solubility and diftusion coefficient with temperature ${ }^{31}$, we have demonstrated the application of temperature-dependent mass-transfer analysis of solubility-limited species from borosilicate glass waste in a basalt repository. ${ }^{30,31}$

Calculation of the effect of repository heating on the rate of diffusive mass transfer of soluble specieg into the rock is simpler ${ }^{32}$ because the only parameter affected by temperature is the diffusion coefficient, if the retardatian coefficient can be assumed constant. At very early times the bigher diffusion coefficient causes greater mass transfer rate from the waste-package water into the surrounding rock, depleting the concentration in the waste-package water. This early depletion results in a later mass-transfer rate that is luwer th:sn would occur if the temperature were always at the ambient temperature. Thus, for most time: of interest, the release rate predicted by using a diffusion coeficient evaluated at ambient temperature is conservatively higher than the release rates corrected for repository heating.

\section{Constant and Uniform Chemical Environment}

In predicting the dissolution rate of low-solubility species it is important to examine the possibility of solubility changing with time, due to changes in the local chemical environment. For example, dissolution of borosilicate glass waste causes local changes in $\mathrm{pH}$, which affects solubility of several species. Also, the oxidizing environment due to air during construction and waste emplacement can revert to a more reducing environment after repository sealing and resaturztion, resulting in large changes in solubility of uranium and other species. If the chemical environment stabilizes within a few hundred years, while the protective container is still effective, the solubility corresponding to the stabilized environment would be the appropriate value to use in predicting release rates.

A longer-term mechanism for changing the chemical environment is the radiolysis of ground water due to alpha particles from transuranics in the dissolving waste. If radiolytically-produced hydrogen can escape, radiolytic peroxide can result in a locally oxidizing environment and greater solubilities of uranium, particularly important in predicting the long-term release rate from spent fuel. Neretnieks ${ }^{33}$ has analyzed the progress of such a redox front for a spent-fuel repository in granite, determined by the rate of peroxide generation, mass transfer of the peroxide from the wast.e surface, and reaction of peroxide with ferrous compounds in the water and rock. The result is a moving and expanding redox front, a transition from the oxidizing region of high uranium solubility near the waste surface to the low-solubility reducing region. To predict the net rate of release of uranium across this front, the equations for mass-transfer of low-solubility species can be applied, using the radius of the redox front as the geometrical parameter.

Alpha radiolysis can affect the release of other constituents from the uranium-dioxide matrix in spent fuel. If the species dissolve congruently with the uranium, they will dissolve at a rate controlled by the ligher solubility of uranium at the waste surface. If these species do not precipitaie at the redox front, alpha radiolysis will have resulted in a greatly increased release of contained ractioactive species to the geosystem.

$d$ partly failed iron container may prevent the radiolytically generated oxidant from moving into the rock, and corrosion products may decompose peroxide oxidants, but it is still possible that radiolysis can create a locally oxidizing environment neat the spent fuel surface that accelerates release of constituents from the spent fuel matrix. ${ }^{34}$

\section{MASS TRANSFEL WI'H BACKFIL BETWEEN WASTE SOLID AND ROCK}

\section{Steady-State Mats Transfer Through Backfll}

We have obtained the solution to the steady-state mass transfer rate from a waste solid, through surrounding backfill, and into porous ror'" ". and the results have been illustrated, as a function of the backfillto-rock porosity ratio and the Peclet meruoer. For equal porosities of backfill and rock, backfill reduces the 
mass transfer rate into rock because of the assumed zero fow in the backfill. For backfill of much greater porosity than rock, as may be expected for backfill now contemplated in U.S. repositories, increasing the backfill thickness increases the rate of mass transfer into the rock, a consequence of the increasing area of the backfill-rock interface as the backfill thickness is increased. Unless the backfill can be made far less porous than the rock, introducing backfill cannot be expected to result in large reductions in the steady-state rate of release of stable and long-lived species into the rock, assuming that the chemical environment remains the same.

When radioactive decay is included in the analysis of steady-state mass transfer, the retardation coefficient also appears. The results demonstrate that a sorbing backfill does not necessarily reduce the steadystate release rate into surrounding rock.

\section{Time-Dependent Masn Trangfer of Solubllity-Limited Radionctive Specles Through Baciffll}

The equations for the time-dependent diffusive transport of radioactive species through backfill have been developed for solubility-limited species ${ }^{22,35,36}$ and for the rapidly dissolving "gap" activity in spent fuel. ${ }^{13}$ The equations are applicable for a radioactive species with no decay precursor and for diffusion-dominated mass transfer through the backfill and the surrounding porous rock.

During the early times of transient dissolution a higher backfill porosity greatly increases the dissolution rate, because the early resistance to mass transfer is entirely within the backfill. For typical backfill properties and for a reiardation coefficient of 1000 the mass-transfer rate into the rock closely approaches that into the backfill after about $10^{4}$ years, and steady state is reached after about $10^{5}$ years.

Increasing sorption steepens the transient concentration gradient and increases the tiate of diffusive mass transfer. Steady-state rates of mass transfer of stable species are not affected by sorption. For a given backfill retardation, increasing sorption by rock increases the maximum rate of mass transfer into the rock, showing that the rock properties and finite backfill must be included in the analysis, as has been done here. For typical parameters, the maximum rate of mass transfer into the rock depends mainly on the backfill retardation.

For neptunium-237, with a half life of $2.1 \times 10^{6}$ years, corrections for decay are minor. For carbon-14, with a half life of 5730 years, decay not only increases the rate of mass transfer into the backfill, because it stcepens the concentration profile, but it also increases the transient and steady-state rates of mass transfer into the rock. For a radionuclide half life as short as $\mathbf{1 5 . 3}$ years, decay considerably increases the mass transfer rate into the backfill, but the half life is short enough that the species all decays while diffusing in the backfill. Thus, there is a range of half lives for which the rate of mass transfer into the rock is greater than the steady-state value for no decay. As illustrated here for carbon-14, some radionuclides important in repository performance analysis will fall within this range.

Previous backfill analyses $37,38,39$ have calculated the "breakthrough" time for a stable species at a specified distance in a backfill of infinite thickness and have used that time to estimate the amount of radioactive decay that will occur during diffusion through finite backfill in a repository. This has led to considerable overestimates of the possible retention of radionuclides in backfill. Mass-transfer analysis that take into account the diffusive properties, of the rock should be used to predict release of radionuclides through a backfill of finite thickness.

\section{Time-Dependent Mass Trensfer of Soluble Rndlonctive Specles Through Backfll}

We lave given analytical solutions for the time-dependent diffusion of readily soluble "gap" activity through backlill and into surrounding porous rock. Illustrative results ${ }^{-10}$ for a 30 -cm layer of backfill of porosity 0.2 and 1 percent release of soluble species to the fuel-cladding gap slow that nonsorbing jodine- 129 arrives at the backfill-rock interface in less than a year, with a peak release rate about ten-fold less than the "quivalent release-rate limit calculated from the USNRC criterion., ${ }^{14}$ The peak release rates of the sorbing cesium isotopes into rock, with an assumed retardation coefficient of 1000 , occur at about 100 years. The normalized release rate of cesium-137 is less than that of cesium-135 because of decay in the backfill. The 
peak release rate of cesium-135 is about 10 -fold less than its release-rate limit. The release limit is exceeded for cesium-137 if an appreciable number of waste containers fail not long, after emplacement. For these parameters, backfill several times thicker than in current repository designs would be needed for each waste package to comply with the release-rate criterion if no container is assumed, but the present designs should be adequate for cesium-137 if all waste containers last 300 years or more.

\section{Effect of Non-Linear Sorption on Mise Transfer Through Baciefll}

In the previous analyses we have assumed linear sorption in the backfill, as expressed by a retardation constant independent of concentration. Some data show nonlinear sorption in bentonite, with a tendency cowards saturation of the sorption sites. For such backfill materials, the mass-transfer characteristics can be far different than those analyzed above for linear sorption. Species can be released sooner and more rapidly into the rock if sorption saturation occurs in the backfill. Analytical solutions for a mass transfer with a simplified nonlinear sorption isotherm have been given. ${ }^{22,41}$

\section{Effect of Flow In Bachfil}

The above analyses have assumed no ground-flow in backfill. Flow in backfill is not expected to be important in U.S. repositories because of the very low flow in the surrounding rock. In the Swedish program, where greater ground-water flow is expected, the planned backfill is compacted bentonite, of low enough permeability to result in the negligible backfill water flow that is assumed in their mass-transfer analysis 2. From our analysis ${ }^{42}$ of water flow through a spherical shell of backfill surrounded by rock, the effect of backfill water flow can be predicted.

\section{MASS TRANSEER IN ERACTURED ROCK}

Neretnieks ${ }^{2,43,44}$ has developed an equation for steady-state mass transfer through beckfill into ground water in discrete fractures, using boundary-layer approximations. The initial purpose was to predict the lifetime of a thick copper canister by predicting the rate of mass transfer of sulfide oxidant from ground water to the canister surface. The boundary-layer approximation does not apply for very small fracture-flow Peclet numbers, characteristic of U.S. repositories.

We have developed the solutions for time-dependent transport through backfill into a fracture with flow ${ }^{\text {t5 }}$ and for transient diffusion from a waste solid with fractures in porous rock, with negligible water flow in the fractures. ${ }^{46}$ These new analyses allow greater realism in predictions for U.S. repositories, and they also establish the region of validity of the earlier analyses of mass transfer into surrounding porous media.

\section{MASS TRANSFER OF RADIOACTIVE DECAT CAAINS}

To predict the time-dependent mass transfer of a radioactive species that is a daughter in a radioactive decay chain with long-lived precursors, it is necessary to include the simultaneous transport and decay of the precursors. We have published elsewhere ${ }^{47}$ the fundamental equations for advective transport of decay chains in infinite media. Chambre has developed analytical solutions ${ }^{36}$ to predict the release rates of decay chains with arbitarily many members into porous tock from backfill of finite thickness. The predicted spacedependent concentrations at 1000 years after the beginning of dissolution, using Bateman-type boundary cuncentrations, are illustrated ${ }^{\text {td }}$ for the decay chain

$$
{ }^{234} \mathrm{U} \rightarrow{ }^{230} \mathrm{Th} \rightarrow{ }^{326} \mathrm{Ra}
$$

A ppreciable concentrations of ${ }^{226} \mathrm{Ra}$ near the backfill-rock interface are a consequence of the presence there of its precursors. The greatest relense rate of ${ }^{226} \mathrm{Ra}$ occurs at about $2 \times 10^{5}$ years. 


\section{RELEASE RATES FROM WASTE PACKAGES IN A SALT REPOSITORT}

\section{The Mass-Transfer Appronca}

In 1985 we proposed ${ }^{49}$ a realistic and direct approach towards predicting radionuclide release rates in a salt repository based on mass-transfer analysis. Recognizing that within a few years after the emplacement of waste packages in a geologic repository salt creep is likely to close the air gap between a waste container and t! $:$ - borehole wall, we proposed that thereafter release rate of dissolved species from the waste solid is likely to be governed by mass transfer into brine in grain boundaries in the surrounding salt and in intersecting interbeds of other rock. Because of the low expected migration velocities of brine in the consolidated salt, mass transfer dominated molecular difiusion was a likely possibility. If so, many of the mass-transfer analyses described above could be adapted to predicting release rates in a salt repository.

Subsequent analyses of creep closure and consolidation by Brandshaug ${ }^{30}$ confirms that consolidation is expected within a few years after emplacement.

\section{Brine Migration Velocities}

During the consolidation period most of the brine inclusions in salt crystals near the waste package are predicted to have moved to grain boundaries under the influence of temperature gtadients. After salt consolidation brine in grain boundaries near the waste package can only migrate outward into the surrounding salt, under the influence of pressure gradients caused by transient heating of the salt. Ilot salt near the waste package expands against the waste package and surrounding salt, resulting in high compressive stresses near the waste package. Grain-boundary brine expands more than does the salt and further increases the local pressures and pressure gradients that cause brine to flow outward into the cooler salt. Sucli outward flow of brine relieves the pressure gradient on the fluid, which finally relaxes to near-lithostatic pressure.

To determine the extent to which advection by brine in grain boundaries is an important transport mechanism for released radionuclides, we have estimated the time-dependent migration of brine after salt ronssolidation. Based on current interpretations of experimental data on the migration of grain-boundary brine in natural salt deposits, it is assumed that the migration velocity is proportional to the local gradient in fluid pressure. To find the t. re-dependent pressure profile, we have adopted the governing equations for the theromoelastic stresses and deformation of salt due to inermal expansion of the salt and of its contained grain-boundary brine developed by McTigue. ${ }^{\text {s1 }}$ Based on calculated time-dependent temperature profiles in the salt after waste emplacement and utilizing thermoelastic and permeability parameters deduced by Mr'Tigue for salt at the Waste Isolation Pilot Plant in New Mexico, our anslytical solutions for the timedependent profiles of pressure and brine velocity provide means to estimate the effect of brine migration on radiontrclide release to salt. ${ }^{52}$ Consolidation is assumed to have occurred instantaneously. We assume, conservatively, that the waste container has completely failed during consolidation or shortly thereafter.

With these parameters, the brine migration velocity is nearly zero after ten years. Even tbe highest velocity is of the order of millimeters per year and occurs only with a meter or so of the waste package. 'The predicted velocities are so low that molecular diffusion may be the dominant transport process for radionuclides in salt. This is likely to be true if the diftusion coefficient is near $10^{-5} \mathrm{~cm}^{2} / \mathrm{sec}$, a typical value for a liquid continuum, or even if it is reduced a hundred-fold by tortuosity.

More realistically, if the waste container is effective for several tens or hundreds of years, the temperature and pressure gradients will have relaxed and the migration velocities are expected to be so low that convective transport seems even less tikely.

These conclusions are tentative, however, because of the considerable uncertainties in the appropriate properties of sall to be used in the calculation of pressure gradients and velocitieg.

\section{Releare Rates by Dlffusion}

As a result of the foregoing analysis of brine migration, we assume that after salt consolidation mass 
transfer of dissolved species away from the waste solid is governed by molecular diffusion, so that the equations for the time-dependent diffusive transfer of dissolved species from a waste solid into porous rock can be applied. The waste container is conservatively to have failed during consolidation, or shortly thereafter, so that brine at the waste surface begins to dissolve the spent-fuel waste and its contained radioactive species. Assuming a waste solid $0.72 \mathrm{~m}$ in radius, a diffusion coefficient of $10^{-7} \mathrm{~cm}^{2} / \mathrm{sec}$, salt porosity of 0.001 , a uranium retardation coefficient of 20 , and uranium solubility of $0.001 \mathrm{~g} / \mathrm{m}^{3}$, we estimate the fractional release rate for uranium of the order of $10^{-12} / \mathrm{yr}$ and less. ${ }^{9}$

Similarly, applying the equations for the time-dependent diffusive release of the readily-soluble gap inventory of cesium and jodine, assuming that one percent of the initial iodine and cesium is in the readily soluble form and assuming $0.45 \mathrm{~m}^{3}$ of void water in the failed waste package, we obtain fractional release curves for I-129, Cs-135, and Cs-137 similar to those shown in Figure 1, but of lower magnitude because of the expected lower diftusion coefficient.

To estimate the release rates from a waste package into more porous interbeds that may intersect the borehole in a salt repository, we can apply our new analytical solution for the time-dependent transport from a waste cylinder into a fracture with negligible water flow.

\section{DIFFUSION-LIMTED RELEASE RATES FROM WASTE PACKAGES IN A TUFF REPOSITORY}

The design for a waste repository in unsaturated tuft provides an air gap between each waste package and the surrounding rock. Infiltration water can drip on the waste package. Ditring the thermal period the hot waste evaporates infiltration water at atmospheric pressure, resulting in no liquid pathways for transport of radionuclides from the waste package. The tuff project ${ }^{3}$ estimates later liquid releases of dissolved radionuclides from a waste package by multiplying saturation concentrations of waste constituents by the volume flow rate of ground water contacting each waste package. The simple predictive theory seems reliable and requires only data on flow rate and saturation concentrations. It also requires validation that the porous rock does not contact the waste package or that the annular gap does not fill with sediments. Otherwise, diffusion pathways for dissolved species on the waste surface into ground water in the partly saturated pores of the surrounding rock can result in transient diffusive mass-transfer rates as much as three orders of magnitude greater than the bulk-flow solubility-limited release rate at the low flow rates predicted for the tuft repository, depending on the magnitude of the diffusion coefficient. Therefore, key issut's of validating waste-package release rate predictions include the long-term integrity of the air gap and the diffusion coefficient for dissolved species in turt.

The tuff project also presents ${ }^{53}$ an alternative est imate of the release rate from a waste package in contact wit $h$ moist tuff, based on a mass-transfer equation ${ }^{7,8}$ aeveloped from a boundary-layer approximation. As has been pointed out earlier, it is invalid to apply such equations developed from boundary-layer approximations to predict mass transfer at the low water infiltration rates (ca. 0.003 to $1 \mathrm{~mm} / \mathrm{yr}$ ) estimated for the tuff project. Also, it is nonconservative to apply the equation for steady-state mass transfer, developed from bonndary layer theory, because the transient release rates will be much higher than the steady-state rate for a very long period.

Our estimates for the possible release rates for a tuff repository, assuming conservatively that there are liquid diffusive pathways into the surrounding rock, are based on applying the equations for diffusiverontrolled mass transfer discusse: insein. The preliminary results for solubility-limited dissolution of spent fuel, based on solubility and porosity used by the tuff project and assuming a diffusion coefficient of $10^{-5}$ $\mathrm{cm}^{2} / \mathrm{sec}$, predict diffusion-controlled release rates over 1000 -fold greater than those estimated elsewhere, ${ }^{53}$ but still within regulatory limits. Corrections for the time-dependent repository temperatures lave not been inclualed in these preliminary estimates. 


\section{RELEASE RATES EROA WASTE PACKAGES IN A BASALT REPOSITORT}

Most of the mass-transfer analyses and topics discussed herein have been illustrated with data expected to be representative for a repository in basalt. Predictions from these analytical solutions can be used as an independent check of the numerical calculations made by the project. The more extensive mass-transfer analyses reported herein, such as the effect of repository heating and the transport of radionuclide decay chains, as well as the effect of discrete fractures in the rock, can be applied to the performance assessment of a basalt repository.

\section{ACENOWLEDGEMENT}

Work supported in part by the U. S. Department of Energy via Contract DE-AC03-76SF00098.

\section{REFERENCES}

1. U.S. Nuclear Regulatory Commission, "Disposal of High-Level Radiaactive Wastes in Geolugic Repositories - Technical Criteria," 10 CFR 60, Fed. Reg., 48, 120, 18194, 1933.

2. I. Neretnieks, "Transport of Oxidants and Radionuclides Through a Clay Barrier," Report KBS TR-79, February 1978

3. T. H. Pigford, J. O. Blomeke, T. L. Brekke, G. A. Cowan, W. E. Falconer, N. J. Grant, J. R. Johnson, J. M. Matusek, R. R. Parizek, R. L. Pigford, D. E. White, A Study of the Isolation System for Gealogic Disposal of Radioactive Wastes, National Academy Press, Washington, D.C., April 1983.

4. P. L. Chambré, T. H. Pigford, S. Zavoshy, "Solubility-Limited Dissolution Rate in Groundwater," Trans. Amer. Nucl. Soc., \&9, $153(1982)$.

5. P. L. Chambré, T. H. Pigford, Y. Sato, A. Fujita, H. Lung, S. J. Zavoshy, R. Kobayashi, Analytical Performance Models, Lawrence Berkeley Laboratory Report LBL-14842, 1982.

6. M. S. Bensky and D. L. Oliver, "Transient Diffusional Release From Waste Packages in a Repository in Basalt", Proceedings of the Materials Research Sociefy, Scientific Basis for Nuclear Waste Manugement I.Y, 1986.

7. J. F. Kerrisk, "Solubility Limits on Radionuclide Dissolution," Proceedings of the Materials Research Suciety, Scienlific Basis for Nuclear Waste Management VIII, C. M. Jantzen, J. A. Stone, R. C. Ewing, e.1s., 44, 237-244, 1985.

8. J. F. Kerrisk, "Solubility Limits on Radionuclide Dissolution Ai a Yucca Mountain Repository," Report LA-9995-MS, May 1984.

9. P. L. Chambre, Y. Hwang, W. W.-L. Lee and T. H. Pigford, "Release Rates from Waste Packages in a Salt Repository." Trans. Am. Nucl. Soc., 55, 131-132 (1987).

10. A. M. Liebetrau, M. J. Apted, D. W. Engel, M. K. Altenhofen, C. R. Reid, D. M.Strachan, R. L. Erikson, and K. I. Jolınson, "The Analytical Repository Sourte-Term (AREST) Model: Description and Documentatuion," Pacific Northwest Laboratory Report PNL-6346, 1987.

11. N. C. Garisto and D. M. LeNeveu, "A Vault Model for the Assessment of Used Fuel Disposal in Canada," Proceedings of the .Vaterials Research Society, Scientific Basts for Vuclear Waste Management .M. M. J. Apted and $R$. E. Westerman, eds., 1988.

12. R. J. Ilopkirk, D. J. Gilby and W. H. Wagner, Modelling of Solute Transport in the Near Fieid of a High Level Waste Repository," Report 85-26, Polydynamics Ltd, Zurich, 1986.

13. C. L. Kim, P. L Chambré and T. H. Pigford, "Mass-Transfer-Limited Relerse of a Soluble Waste 
Species," Lawrence Berkeley Laboratory Report LBL-20899, June 1986.

14. T. H. Pigford, "Can Cs-137 be Dismissed Under the NRC Release-Rate Criterion for Geologic Repositories," Report UCB-NE-4088, July 1986.

15. J. I. Scott and C. M. Koplik, "Analytic Models for Assessing the Performance of Engineered Barriers in a Basalt Repository," Proceedings of the Materials Research Society, Scientific Basis for Nuclear Waste Management VII, G. L. McVay, ed., 26, 1077-1084, 1984.

16. B. Ross, "Models for Calculating Dissolution Rates of High-Level Waste," Nuclear Safety, 28, 362-373, September 1987.

17. S. J. Zavoshy, P. L. Chambré, and T. H. Pigford, "Mass Transfer in a Geologic Environment," Proceedings of the Materials Research Society, Scientific Basis for Nuclear Waste Management VIII, C. M. Jantzen, J. A. Stone, R. C. Ewing, eds., 44, 311-322, 1985.

18. L. R. Pederson, C. Q. Buckwalter and G. L. McVay, "The Effect of Surface Area to Solution Volume on Waste Glass Leaching," Nucl. Tech., 62, 151 (1983).

19. A. E. van Luik, M. J. Apted, W. J. Bailey, J. H. Haberman, J. S. Shade, R. E. Guenther, R. J. Serne, E. R. Gilbert, R. Peters, R. E. Williford, "Spent Nuclear Fuel as a Waste Form for Geologic Disposal: Assessment and Recommendations on Data and Modeling Needs," Report PNL-6329, 1987.

20. P. L. Chambré, C. H. Kang, W. W.-L. Lee and T. H. Pigford, "The Role of Chemical Reaction in Waste-Form Performance," Proceedings of the Materials Research Society, Scientific Basis for Nuclear Wasle Management XI, M. J. Apted and R. E. Westerman, eds., 1988.

21. D. Rai and R. G. Strickert, "Maximum Concentrations of Actinides in Geologic Media," Trans. Amer. Vucl. Soc., 99, 185 (1980).

22. P. L. Chambré and T. H. Pigford, "Prediction of Waste Performance in a Geologic Repository," Proceedings of the Materials Research Society, Scientific Basis for Nuclear Waste Management VIII, G. L. McVay, ed, 26, 985-1008, 1984.

23. T. K. Sherwood, R. L. Pigford, and C. R. Wilke, Mass Thansfer, 129-137, McGraw-Hill, New York, 1975.

24. I1. O. Pfannkuch, "Contribution a l'etude des deplacement de fluides miscible dans un nilieu poreux," Rev. Inst. Fr. Petrol., 18(g), 215 (1982).

25. C. II. Kang, P. L. Chambré, T. H. Pigford, "One-Dimensional Advective Transport with Variable Dispersion," Trons. Am. Nucl. Soc., 50, 140-141 (1985).

26. U.S. Department of Ënergy, "Environmental Assessment: Reference Repository Location, Hanford Site, Whishington," Ruport DOE/RW-0070, 2, 1986.

27. T. II. Pigford, P. L. Chambré, M. Albert, M. Foglia, M. Harada, F. Iwamoto, T. Kanki, D. Leung, S. Misuda. S. Muraoka, and D. Ting, Migration of Radionuclides Through Sorbing .Media: Analylical Siulutions - II, Lawrence Berkeley Laboratory Report LBL-11616, October 1980.

28. C. L. Kim, P. L. Clianabré, WV. W.-L. Lee and T. H. Pigiord, "Radionuclide Transport From an Array of Waste Packinges in a Geologic Repository," Trans. Am. Nucl. Soc., 54, 109 (1987).

29. J. Aln, P. L. Chambré, T. II. Pigford and WV. W.-L. Lee, "Radionuclide Dispersion From Multiple Patch Sousces luto a Rock Fracture," Report LBL-23425 (1987).

30. P. L. Clianbré, W. J. Williams, C. L. Kim and T. H. Pigford, "Time-'Temperature Dissolution and Radionuclide Transport," Trans. Am. Nuc. Soc., $\{6,131$ (1984).

31. 'T. H. Pigford, P. L. Chambré, and S. Zavoshy, "Effect of Repository Heating on Dissolution of Glass Waste," Trans. Am. Nucl. Soc., f4, 115 (1983). 
32. C.-L. Kim, P. L. Chambré, W. W.-L. Lee, and T. H. Pigford, "Variable Temperature Effects on Release Rates of Readily Soluble Nuclides," Lawrence Berkeley Laboratory Report UCB-NE-4115, 1987.

33. I. Neretnjeks, "Migration model for the near field, Final Report," KBS Report 82-24, (1982).

34. N. C. Garisto, K. B. Harvey, F. Garisto and L. M. Johnson, "Source Term Models for the Assessment of Nuclear Fuel Waste," Proc. Waste Management '86, 397-401, Tucson, Arzona, 1986.

35. P. L. Chambre, H. Lung, and T. H. Pigford, "Time-Dependent Mass Transfer Through Backfill," Trans. Amer. Nucl. Soc., 46,132 (1984).

36. P. L. Chambre, T. H. Pigford, W. W.-L. Lee, J. Ahn, S. Kajiwara, C. L. Kim, H. Kimura, H. Lung, W. J. Williams, and S. J. Zavoshy, Mass Transfer and Transport in a Geologic Environment, Lawrence Berkeley Laboratory Report LBL-19430, 1985.

37. E. J. Nowak, "The Backfill Barrier as a Component in a Multiple Barrier Nuclear Waste Isolation System," Sandia National Laboratories Report SAND 79-1109, October 1978.

38. T. M. Ahn, K. S. Czyscinski, E. M. Franz, C. J. Klamut, B. S. Lee, N. S. Mclntyre, K. J. Swyler, R. J. IVilke, "Nuclear Waste Management Technical Support in the Development of Nuclear Waste Form Criteria for the NRC." Report NUREG/CR-23333, Vol. 4, 1982.

39. T. M. Ahn, R. Dayal, and R. J. Wilke, "Evaluation of Backfill as a Barrier to Radionuclide Migration in a High Level Waste Repositcry," Appendix A in: Dayal, et al., "Nuclear Wagte Management Technical Support in the Development of Nuclear Waste Fonn Criteria for the NRC," Task l, Waste Package Overview, Report NUREG/CR-2333, BNL-NUREG-51458, Vol. 1, 1982.

40. P. L. Chambré, C. II. Kang, W. W.-L. Lee and T. H. Pigford, "Mass Transfer of Soluble Species Into Backfill and Rock," Trans. Amer. Nuc. Soc., 59, 136 (1986).

11. H. C. Lung, P. L. Chambré, T. H. Pigford, "Nuclide Migration in Backfill With a Nonlinear Sorption Isotherm," Trans. Amer. Nucl. Soc., 15, 107 (2383).

42. P. L. Chambri, C. H. Kang and T. H. Pigtord, "Flow of Ground Water Around Buried Waste," Trans. Am. Nuc. Soc. 52,77 (1986).

43. I. Neretnieks, "Stationary Transport of Dissolved Species in the Backfill Surrounding a Waste Canister in Fissured Rock: Some Simple Analytical Solutions," Nucl. Techrol., 72, 194 (1986).

14. 1. Vrretnieks, "Source Term Modeling in the KBS-3 Study," Proceedings of the Workshop on the Source Term for Radionuclide Migration from High-Level Waste or Spent Fuel Under Realistic Repository ronditions, Albuquerque, November 1984, pp. 41-68, Report SAND85-0380.

45. C. H. Kang, P. L. Chambré, W. W.-L. Lee and T. H. Pigford, "Time-Dependent Nuclide Transport Turough Backfill into a Fracture," Trans. Am. Nucl. Soc., 55, 134-136 (1987).

16. J. Ahn, P. L. Chanté and T. If. Pigford, "Transient Diffusion From a Waste Solid Into Fractured Porous Rock," Lawrence Berkeley Laboratory Report LBL-24576, 1987.

I7 M. Harada. P. I. Chambré, M. Foglia, K. Higashi, F. Iwamoto, D. Leung, T. It. Pigford, and D. 'Ting, IItgration of Radionuclides Through Sorbing Media: Analylical Solutions - I, Lawrence Berkeley L.iboratory Report 1.131,-10500, Fobruary 1980

Is P. L. Chimbrit. H. C. Lung and T. H. Pigford, "Mass Transfer of a Ratdioactive Decay Chain Through Iatckfill." Trans. Am, Nucl. Soc., 5\%, 78-80 (1986).

41). 'T. H. Pigford and P. L. Chambré, "Mass Transfer in a Salt Repository," Lawrence Berkeley Laboratory Nipport LBL-19918, May 1985.

.11. I. Brandshaug, "Estimate of Consolidation of Crushed Salt Around a Spent Fuel Waste Package," RE/SPEC Ruport RSI-315, 1987. 
51. D. T. MeTigue, "Thermoelastic Response of Fluid-Saturated, Porous Rock," J. Geophy. Res., 91, B9, 9533 (1986).

52. Y. Hwang, P. L. Chambré, W. W.-L. Lee and T. H. Pigford, "Pressure-Induced Brine Migration in Consolidated Salt in a Repository," Trans. Am. Nucl. Soc., 55, 132 (1987).

53. U.S. Department of Energy, "Environmental Assessment: Yucca Mountain Site, Nevada Research and Development Area, Nevada," Report DOE/RW-0073, $2,1986$. 